\title{
A Technique Which We Should Consider More: Temporary Cutaneous Ureterostomy
}

\author{
(D) Burak Çıtamak, (D) Hasan Serkan Doğan, (D) Taner Ceylan, (D) Meylis Artykov, (D) Serdar Tekgül \\ Hacettepe University Faculty of Medicine, Department of Urology, Ankara, Turkiye
}

What's known on the subject? and What does the study add?

Cutaneous ureterostomy $(\mathrm{CU})$ is an easy method of decompressing the upper urinary system. Although the techniques and methods have changed over the years, CU still protect the patients from possible damages.

\begin{abstract}
Objective: To evaluate the feasibility, efficacy and complications of cutaneous ureterostomy (CU) in different indications.

Materials and Methods: Data from 83 patients who underwent CU between 1991 and 2019 were reviewed retrospectively. Patients with neurogenic bladder, posterior urethral valves, solitary kidney and bilateral kidney involvement were excluded. A total of 53 patients aged $<2$ years were included in the analysis. Indications to perform CU were ureterovesical junction obstruction (UVJO) and high-grade vesicoureteral reflux (VUR) with dilatation. Ureteroureterostomy or ureteroneocystostomy methods were preferred for undiversion according to the dilatation status of the ureter. Results: The mean patient age was $4.47 \pm 3.6$ months, 40 (75.5\%) were male and $13(24.5 \%)$ were female. The mean follow-up time was $57.4 \pm 41.4$ (6-150) months. Loop and end CU were performed in 18 (34\%) and 35 (66\%) patients, respectively. The indications for CU were UVJ0 in 26 (49\%) and high-grade VUR in 27 patients. Two (3.7\%) patients needed dilatation because of stenosis that occurred after CU. Within the follow-up time, 39 patients underwent undiversion. The clinical improvement rate was $94.3 \%$.

Conclusion: $\mathrm{CU}$ is a simple method with satisfactory results when performed in patients with megaureter and massive dilatation. Despite the less frequent use, it is still an important alternative to the increasingly used conservative methods.

Keywords: Cutaneous ureterostomy, urinary diversion, hydronephrosis, megaureter, vesicoureteral reflux, ureterovesical junction obstruction
\end{abstract}

\section{Introduction}

Megaureter arises from a functional or anatomical abnormality of the ureterovesical junction and is classified according to the presence of reflux or obstruction (1). Smith classified megaureters into four categories, namely, obstructed, refluxing, refluxing with obstruction and non-refluxing/non-obstructing. Later, King subdivided megaureters into primary and secondary $(1,2)$. Ureteric diameter $>7 \mathrm{~mm}$ was defined as abnormal $(3)$, and it is often diagnosed in the infantile period and regresses is most cases. In the vast majority of patients, a megaureter does not lead to clinical problems and loss of renal function $(4,5)$. However, surgical intervention may be necessary when progressive massive dilation and loss of renal function occur. Cutaneous ureterostomy (CU) is a simple method of decompressing the upper urinary system (6). Although the techniques and methods have changed over the years, CU still protects the patients from possible kidney damage. Thus, this study aimed to evaluate the feasibility, efficacy and complications of CU in patients with vesicoureteral reflux (VUR) and ureterovesical junction obstruction (UVJO) and extremely dilated ureters.

\section{Materials and Methods}

Data from 83 patients who underwent CU between 1991 and 2019 were reviewed retrospectively. Patients with neurogenic bladder $(n=10)$, posterior urethral valves $(n=12)$, solitary kidney $(n=2)$ and bilateral $\mathrm{CU}$ cases $(n=4)$ were excluded from this study.

Correspondence: Burak Çıtamak MD, Hacettepe University Faculty of Medicine, Department of Urology, Ankara, Turkiye Phone: +90 3123051969 E-mail: burakcitamak@gmail.com ORCID-ID: orcid.org/0000-0002-7341-8753

Received: 11.07.2020 Accepted: 05.09.2020

Cite this article as: Çıtamak B, Doğan HS, Ceylan T, Artykov M, Tekgül S. A Technique Which We Should Consider More: Temporary Cutaneous Ureterostomy. J Urol Surg 2021;8(2):118-122.

${ }^{\circ}$ Copyright 2021 by the Association of Urological Surgery / Journal of Urological Surgery published by Galenos Publishing House. 
In total, 53 patients aged $<2$ years were included in the analysis. After diagnosis, all patients were started antibiotic prophylaxis. Surgery was performed in two groups of patients: primary highgrade VUR group and UVJO group. Indications for surgery were refractory urinary tract infection (UTI) in patients with VUR and increasing severity of hydronephrosis (HN) in patients with UVJO who were unsuitable for reimplantation into a small bladder. Ultrasonography (US) is the primary imaging modality in the prenatal period and initial study in the symptomatic group. Voiding cystourethrography (VCUG) was performed to assess for the presence of VUR and to further delineate the anatomy of the bladder and outlet. Mercaptoacetyltriglycine-3 scintigraphy was used to evaluate and follow the obstruction status. After the loop or end $\mathrm{CU}$, the patients who have shown resolution of the dilatation in the renal unit and completed their bladder development underwent undiversion procedures. The choice of the UC type mostly depends on the underlying pathology. In patients with primary UVJO, we tried to perform end UC as the standard approach. However, at the beginning of this series, some patients with VUR underwent end CU. As the experience improved over time, we started to perform loop CU to understand whether it may be a good alternative that keeps the chance of further ureteroureterostomy without bladder surgery in some patients whose VUR was resolved. In every patient, diagnostic cystoscopy is performed, the ureter is catheterised with a 3-Fr or 4-Fr catheter, a retrograde pyelography is performed to visualise the renoureteral unit and the catheter is left in the ureter. The surgery is performed through a $2 \mathrm{~cm}$ incision at the lateral border of Pfannenstiel incision at the lower quadrant with a muscle splitting technique. The peritoneum is deviated medially, and the ureter is found in the retroperitoneal area, turned with a tape and brought outside to the incision. The tortuosity of the ureter is straightened. In end CU, the ureter is ligated at the most distal part, the proximal ureteral end is brought to the incision with the proper length to prevent kinking and a 10-Fr feeding catheter is indwelled into the ureter for 7 days. In loop CU, the ureter is incised by a no.15 scalpel, and the ureter is anastomosed to the skin. Both the proximal and distal parts of ureterostomy are catheterised by an 8-Fr or 10-Fr feeding catheter for 7 days. In both techniques, the ureter is fixed to the fascia with four stitches to prevent the inside retraction of the ureter. The timing of undiversion was decided by evaluating the resolution of HN using US and assessing the bladder volume and shape by VCUG. Ureteroureterostomy and ureteroneocystostomy (UNC) with remodelling methods were preferred for undiversion according to the dilatation status of the ureter. In patients with bilateral kidney involvement, the more affected side in the dimercaptosuccinic acid (DMSA) scan and the side with a higher HN grade on US were chosen for surgical intervention.
Patient demographics, complaints and underlying diseases were recorded preoperatively. After preoperative evaluation using US, VCUG and DMSA or mercaptoacetyltriglycine scan, postoperative follow-up was performed using US at regular intervals. Patients with serum creatinine levels higher than the age-specific reference values were considered to have chronic renal disease. Status of improvement was assessed by the radiological and clinical course of the patient.

Complications were assessed according to the Clavien-Dindo classification. Evaluation of HN grades on US was based on the Society of Fetal Urology (SFU) criteria, whereas the evaluation of VCUG was based on the criteria of the International Reflux Study Committee. This study was approved by the local ethical committee (GO-18/267).

\section{Statistical Analysis}

Statistical analyses were performed using SPSS version 17.0 (SPSS Inc., Chicago, IL, USA). Mann-Whitney, chi-square, Fisher's exact test and t-tests were used where appropriate. P-value $<0.05$ indicated significance.

\section{Results}

The mean patient age at the time of surgery was $4.47 \pm 3.6$ (115) months. The median age was 3 months, 40 (75.5\%) were male and $13(24.5 \%)$ were female. The mean follow-up time was $57.4 \pm 41.4$ (6-150) months.

Indications for CU were primary UVJO and high-grade VUR in 26 and 27 patients, respectively. Moreover, 41 (77.4\%) patients had SFU grade $4 \mathrm{HN}$, while 10 patients had grade $3 \mathrm{HN}$. HN was also detected in the contralateral kidney in 18 patients. Scarring was detected on preoperative DMSA scan in 52.8\% (28/53) of the patients. The clinical improvement rate was $94.3 \%$.

CU was performed in 27 patients with primary VUR (with highgrade reflux causing recurrent febrile UTI), while the clinical or radiological improvement rate was $92.6 \%$ (25/27). The mean patient age was $4.81 \pm 4.3$ months, and loop CU was performed in $59.3 \%(16 / 27)$ of the patients. The mean follow-up time was $68.2 \pm 44.4$ months. Two patients underwent nephrectomy due to loss of renal function.

Furthermore, 26 patients underwent CU for primary UVJO, and the clinical or radiological improvement rate was $96.2 \%$ (25/26). The mean patient age was $4.12 \pm 2.8$ months, and $92.3 \%(24 / 26)$ of the patients underwent end CU. The mean follow-up time was $46.1 \pm 35.3$ months. When patients with primary VUR and primary UVJO were compared, the difference in the type of CU (loop vs end) and presence of a renal scar on DMSA were found significant $(p=0.009, p<0.001)$ (Table 1$)$. 


\begin{tabular}{|l|l|l|l|}
\hline \multicolumn{4}{|l}{$\begin{array}{l}\text { Table 1. Comparison of patients with primary VUR and } \\
\text { primary UVJO }\end{array}$} \\
\hline Patient characteristics & $\begin{array}{l}\text { Primary } \\
\text { VUR }\end{array}$ & $\begin{array}{l}\text { Primary } \\
\text { UVJO }\end{array}$ & p \\
\hline No. of patients & $27(51 \%)$ & $26(49 \%)$ & \\
\hline Mean age (months) & $4.81 \pm 4.3$ & $4.12 \pm 2.8$ & 0.767 \\
\hline Gender (M/F) & $20 / 7$ & $20 / 6$ & 0.810 \\
\hline Renal scar on DMSA (\%) & $70.4 \%$ & $34.6 \%$ & $\mathbf{0 . 0 0 9}$ \\
\hline $\begin{array}{l}\text { Indication for surgery (HN/ } \\
\text { infection) }\end{array}$ & $17 / 10$ & $21 / 5$ & 0.150 \\
\hline $\begin{array}{l}\text { Type of cutaneostomy (end/ } \\
\text { loop) }\end{array}$ & $11 / 16$ & $24 / 2$ & $<0.001$ \\
\hline $\begin{array}{l}\text { Type of undiversion (UNC/ } \\
\text { ureteroureterostomy) }\end{array}$ & $16 / 2$ & $21 / 0$ & 0.206 \\
\hline $\begin{array}{l}\text { Interval between CU and } \\
\text { undiversion (months) }\end{array}$ & $15.4 \pm 10.4$ & $11.9 \pm 6.57$ & 0.460 \\
\hline Mean age at undiversion & $18.5 \pm 8.5$ & $15.9 \pm 7.5$ & 0.269 \\
\hline Mean follow-up (months) & $68.2 \pm 44.4$ & $46.1 \pm 35.3$ & 0.081 \\
\hline $\begin{array}{l}\text { Follow-up (radiological/ } \\
\text { clinical) }\end{array}$ & $20 / 7$ & $24 / 2$ & 0.142 \\
\hline Complication (yes/no) & $0 / 27$ & $3 / 26$ & 0.069 \\
\hline $\begin{array}{l}\text { Clinical or radiologic } \\
\text { improvement (\%) }\end{array}$ & $92.6 \%$ & $96.2 \%$ & 0.575 \\
\hline Postoperative UTI & $7 / 27$ & $8 / 26$ & 0.696 \\
\hline $\begin{array}{l}\text { CU: Cutaneous ureterostomy, VUR: Vesicoureteral } \\
\text { junction obstruction, UTI: Urinary tract infection, DMSA: Dimercaptosuccinic acid, HN: } \\
\text { Hydronephrosis, UNC: Ureteroneocystostomy }\end{array}$ & Ureteroves \\
\hline
\end{tabular}

In this study, loop and end CU were performed in 18 (34\%) and 35 patients, respectively. None of the patients who underwent loop CU and two patients who underwent end CU required revision due to stomal stenosis. In addition, 15 (28.3\%) patients developed postoperative UTI, of which six developed two or more. Postoperative UTI was found in 22.2\% (4/18) of the patients in the loop CU group and in $31.4 \%(11 / 35)$ of the patients in the end CU group. Postoperative UTI was found in 25.9\% (7/27) of the patients in the primary VUR group and in $30.8 \%(8 / 26)$ of the patients in the primary UVJO group (Table 2).

Of the 53 patients who underwent $\mathrm{CU}$, four had follow-up shorter than 6 months. Of the 39 patients $(39 / 53,73.6 \%)$ who underwent undiversion, 37 underwent UNC (Cohen UNC in 30, Lich-Gregoir UNC in 1, Politano-Leadbetter UNC in 3 and extravesical UNC in 3), and ureteroureterostomy was performed in two patients. Ureteroureterostomy was performed in patients with VUR after confirming the complete resolution of VUR by preoperative VCUG and intraoperative positioned instillation of contrast cystography. The mean patient age at undiversion was $17.1 \pm 7.9$ (7-44) months, and the average time between CU and undiversion was 12.7 \pm 7.7 (5-42) months. After undiversion, the clinical or radiological improvement rate and complication rates were 100\% (39/39) and 10.2\% (4/39), respectively. One patient developed postoperative urinoma, and one patient had persistent asymptomatic VUR. Percutaneous nephrostomy was

\begin{tabular}{|c|c|c|c|}
\hline Patient characteristics & Loop CU & End CU & $\mathbf{p}$ \\
\hline No. of patients & $18(34 \%)$ & $35(66 \%)$ & \\
\hline Mean age (months) & $4.2 \pm 3.8$ & $4.6 \pm 3.6$ & 0.554 \\
\hline $\begin{array}{l}\text { Indication for surgery (HN/ } \\
\text { infection) }\end{array}$ & $11 / 7$ & $27 / 8$ & 0.220 \\
\hline $\begin{array}{l}\text { Type of undiversion (UNC/ } \\
\text { ureteroureterostomy) }\end{array}$ & $10 / 2$ & $27 / 0$ & 0.089 \\
\hline $\begin{array}{l}\text { Interval between CU and } \\
\text { undiversion (months) }\end{array}$ & $13.3 \pm 10.5$ & $12.5 \pm 6.3$ & 0.360 \\
\hline Mean follow-up (months) & $59.6 \pm 44.8$ & $56.3 \pm 40.2$ & 0.506 \\
\hline Complication (yes/no) & $18 / 0$ & $32 / 3$ & 0.201 \\
\hline $\begin{array}{l}\text { Clinical or radiologic } \\
\text { improvement }\end{array}$ & $94.4 \%$ & $94.3 \%$ & 0.556 \\
\hline Postoperative UTI & $4 / 18$ & $11 / 35$ & 0.481 \\
\hline
\end{tabular}

performed in one patient for worsening $\mathrm{HN}$ that was resolved during follow-up. One patient underwent reoperation because of Double-J stent (DJS) displacement.

Undiversion was not performed in 14 patients because four patients had follow-up $<6$ months, four patients had kidney function $<10 \%$, two patients had chronic failure and four patients had inadequate bladder volume for undiversion.

\section{Discussion}

$\mathrm{CU}$ is known as an old-fashioned method of decompressing massive dilatation in the ureter presented early in infancy with a high risk of loss of renal function and recurrent febrile UTI. In addition to from $\mathrm{CU}$, various urinary diversions and methods, such as vesicostomy, pyelostomy, DJS insertion, nephrostomy and balloon dilatation, have also been shown to be applicable in megaureters (7-10). However, these methods will not remove the anatomical/functional problem and have lower clinical or radiological improvement rates than $\mathrm{CU}$. CU lowers the pressure of the urinary system without disturbing the bladder function, and under certain conditions, $\mathrm{CU}$ is even successful even when closed only by ureteroureterostomy without reimplantation. In our series, we performed ureteroureterostomy without an additional UNC after CU in two patients, and all patients achieved clinical improvement. This possibly supports the opinion that the anatomical and physiological development of UVJ continues after birth and that CU provides time for this development.

In patients with bilateral high-grade reflux causing recurrent febrile UTI, unilateral loop CU has been a very good temporising diversion by creating a refluxing stoma. The refluxing stoma helps not only the resolution of dilatation in the diverted renal unit but also in the non-diverted contralateral side by reducing the bladder pressures. 
CU aims to relieve obstruction and to prevent the deleterious effect of VUR by avoiding possible side effects of bladder surgery and gain time, specifically in small babies, until definitive ureterovesical junction surgery. The repair can be performed with or without remodelling. Particularly, undiversion is not recommended in children aged $<1$ year because of the unwanted effects on the development of bladder functions $(3,11)$. Massively dilated ureters mostly require tapering surgeries during reimplantation, and temporary $\mathrm{CU}$ has the potential to decrease this necessity. Indeed, our experience revealed that only $25.6 \%$ (10/39) of the patients required tapering during reimplantation.

The choice of the CU type mostly depends on the underlying pathology. End CU may be preferred for patients with UVJO. However, loop CU may be a good alternative, which keeps the chance of further ureteroureterostomy in some patients. For bilateral VUR cases, we often prefer the less functioning kidney for loop CU. This approach enables the cessation of VUR on the worse side and provides effective cycling of the bladder by the urine of the better functioning side and gives the option of performing clean intermittent catheterisation in patients requiring it.

Some studies have reported up to $91 \%$ of clinical or radiological improvement rate in CU with permanent repair $(6,12-14)$. In our series, the overall clinical or radiological improvement rate was $94.3 \%$, while the clinical or radiological improvement rate in 39 patients who underwent undiversion was 100\%.

Some authors have presented balloon dilatation and stent placement both as temporary and definitive treatments for UVJO. Stent placement is not easy as expected in these patients and as described in some series of open stent placement (15). In some cases, stent placement may worsen the patients' condition, cause UTi and will not provide improvement of dilatation. The CU is advantageous in these aspects over stent placement $(9,10)$. Ortiz et al. (16) reported $87.3 \%$ success rate of endoscopic balloon dilatation in patients with obstructive megaureter The postoperative VUR rate was $21.5 \%$ in this series. However only a few studies have reported about balloon dilatation; thus, further studies are needed. Placement of percutaneous nephrostomy can be preferred to provide drainage and evaluate renal function. However, prolonged use of a nephrostomy tube during the waiting period to decrease the ureter calibre may lead to complications, such as infection or tube dislodgement. Lee et al. (17) proposed an alternative temporary solution for infants with UVJO. They created a refluxing ureteral implant by an extravesical approach through a Pfannenstiel incision. It may appear advantageous, as it prevents the anxiety of parents about caring for a CU. However, this approach has associated risk for ureter kinking during bladder filling and emptying. Moreover, it still places the upper tract at risk of VUR. CU enables improvement of ureter calibre for future reimplantation and accurate evaluation of renal function without misinterpretation due to persisting VUR.

\section{Study Limitations}

The main limitation is the retrospective nature of this study and the lack of prospective randomisation or stratification. Another limitation is the lack of data on renal scans and glomerular filtration rate values in each patient, which help in assessing renal function. However, to the best of our knowledge, this is one of the largest series from a single centre. Although CU is a technique that has been described a long time ago, it is an easy and reliable method and helps decrease the pressure of the upper urinary system. Our experience showed that it is a feasible method and can be utilised in patients with certain indications.

\section{Conclusion}

CU is a simple method with satisfactory results when performed in patients with megaureter and massive dilatation. Despite the less frequent use, it is still an important alternative to the increasingly used conservative and minimally invasive methods. CU can be performed with high success rates in patients with primary megaureter with VUR or UVJO.

\section{Ethics}

Ethics Committee Approval: This study was approved by the local ethical committee (G0-18/267).

Informed Consent: Retrospective study.

Peer-review: Externally and internally peer-reviewed.

\section{Authorship Contributions}

Surgical and Medical Practices: B.Ç., H.S.D., T.C., M.A., S.T., Concept: B.Ç., H.S.D., S.T., Design: B.Ç., H.S.D., S.T., Data Collection or Processing: B.Ç., T.C., M.A., Analysis or Interpretation: B.Ç., H.S.D., Literature Search: B.Ç., H.S.D., S.T., Writing: B.Ç., H.S.D., S.T.

Conflict of Interest: No conflict of interest was declared by the authors.

Financial Disclosure: The authors declare that they have no relevant financial.

\section{References}

1. King LR. Megaloureter: definition, diagnosis and management. J Urol $1980 ; 123: 222-223$.

2. Report of working party to establish an international nomenclature for the large ureter. Birth Defects Orig Artic Ser 1977;13:3-8.

3. Farrugia MK, Hitchcock R, Radford A, Burki T, Robb A, Murphy F; British Association of Paediatric Urologists. British Association of Paediatric 
Urologists consensus statement on the management of the primary obstructive megaureter. J Pediatr Urol 2014;10:26-33.

4. Liu HY, Dhillon HK, Yeung CK, Diamond DA, Duffy PG, Ransley PG. Clinical outcome and management of prenatally diagnosed primary megaureters. J Urol 1994;152:614-617.

5. Baskin LS, Zderic SA, Snyder HM, Duckett JW. Primary dilated megaureter: long-term followup. J Urol 1994;152:618-621.

6. Kitchens DM, DeFoor W, Minevich E, Reddy P, Polsky E, McGregor A, Sheldon C. End cutaneous ureterostomy for the management of severe hydronephrosis. J Urol 2007;177:1501-1504.

7. Duckett JW Jr. Cutaneous vesicostomy in childhood. The Blocksom technique. Urol Clin North Am 1974;1:485-495.

8. Schmidt JD, Hawtrey CE, Culp DA, Flocks RH. Experience with cutaneous pyelostomy diversion. J Urol 1973;109:990-992.

9. Carroll D, Chandran H, Joshi A, McCarthy LS, Parashar K. Endoscopic placement of double-J ureteric stents in children as a treatment for primary obstructive megaureter. Urol Ann 2010;2:114-118.

10. García-Aparicio L, Rodo J, Krauel L, Palazon P, Martin O, Ribó JM. High pressure balloon dilation of the ureterovesical junction--first line approach to treat primary obstructive megaureter? J Urol 2012;187:1834-1838.
11. Shokeir AA, Nijman RJ. Primary megaureter: current trends in diagnosis and treatment. BJU Int 2000;86:861-868.

12. Hendren WH. Operative repair of megaureter in children. J Urol 1969;101:491-507.

13. Hanna MK. New surgical method for one-stage total remodeling of massively dilated and tortuous ureter: tapering in situ technique. Urology $1979 ; 14: 453-464$

14. Wacksman J, Gilbert A, Sheldon CA. Results of the renewed extravesical reimplant for surgical correction of vesicoureteral reflux. J Urol 1992;148:359-361.

15. Farrugia MK, Steinbrecher HA, Malone PS. The utilization of stents in the management of primary obstructive megaureters requiring intervention before 1 year of age. J Pediatr Urol 2011;7:198-202.

16. Ortiz R, Parente A, Perez-Egido L, Burgos L, Angulo JM. Long-Term Outcomes in Primary Obstructive Megaureter Treated by Endoscopic Balloon Dilation. Experience After 100 Cases. Front Pediatr 2018;6:275.

17. Lee SD, Akbal C, Kaefer M. Refluxing ureteral reimplant as temporary treatment of obstructive megaureter in neonate and infant. J Urol 2005;173:1357-1360. 